\title{
EELS characterization of zirconium hydrides
}

\author{
On Ting Woo $\left({ }^{1}\right)$ and Graham J. C. Carpenter $\left({ }^{2}\right)$
}

(1) AECL Research, Chalk River Laboratories, Chalk River, Ontario, Canada K0J 1J0

(2) MTL/CANMET, Energy, Mines and Resources Canada, 568 Booth Street, Ottawa, Ontario, Canada K1A 0G1

(Received February 24, 1992; accepted April 06, 1992)

\begin{abstract}
The energy of the first plasmon loss peak has been determined for the $\epsilon$ - Zr hydride phase in pure $\mathrm{Zr}$. The peak energy is sufficiently different from that of the $\delta$-hydride to permit EELS "fingerprinting" with ease using a parallel EELS system, but with greater difficulty using serial EELS, because of drift associated with the slower collection rates. Experiments on $\mathrm{Zr}-2.5 \mathrm{Nb}$ alloys showed that the hydride phases can also be distinguished using EELS, facilitating the analysis of hydride precipitates and blisters in nuclear reactor pressure tubes.
\end{abstract}

\section{Introduction.}

A major application of the electron energy loss spectroscopy (EELS) technique is to analyze for elements of low atomic number that are not detectable by conventional thick-window energy dispersive X-ray spectrometers. Analysis is most commonly performed using the characteristic edges caused by inner-shell ionizations. However, the low-loss peaks that are generated by plasmons (collective oscillations of the valence electrons) have been shown to be useful for quantitative microanalysis in $\mathrm{Al}$ alloys [1] and for phase identification [2].

Zaluzec et al. $[3,4]$ have shown that $\mathrm{Zr}$, Ti and $\mathrm{Mg}$ hydrides give rise to plasmon peaks having characteristic energies that are larger than those of the parent metal. The energy shift may be explained in terms of a change in the density and effective mass of the "free" valence electrons associated with hydride formation.

Because there are three distinct hydrides in both $\mathrm{Zr}$ and $\mathrm{Ti}$, a study was initiated to investigate the possibility of identifying the various hydride species using plasmon EEL spectra. Resolvable shifts in plasmon loss energies of $\gamma$ - and $\delta$-hydrides relative to the parent metal (Ti and $\mathrm{Zr}$ ) were observed, and used for "fingerprinting" the phases [5, 6]. These results also showed that the $\mathrm{Zr}$ and Ti hydride plasmon energies reported in references [3] and [4] were originated from $\mathrm{Zr} \gamma$-hydride and $\mathrm{Ti} \delta$-hydride respectively. In this article, we describe an extension of the EELS plasmon loss 
energy technique to the $\epsilon$-hydride in the $\mathrm{Zr}-\mathrm{H}$ system and demonstrate a practical application to the characterization of the major phases in hydrided $\mathrm{Zr}-2.5 \mathrm{Nb}$. Practical applications would include (a) the rapid identification of hydrides that are responsible for delayed hydride cracking by precipitation of crack tips, and (b) the identification of hydride phases in blisters formed in $\mathrm{Zr}-2.5 \mathrm{Nb}$. Hydride blisters are accumulations of hydride phase that may form at the cold end of a temperature gradient [7]. They were observed in Zircaloy-2 (Zr-1.15 at\% Sn-0.25 at\% Fe-0.18 at\% $\mathrm{Cr}-0.08$ at \% $\mathrm{Ni}$ ) pressure tubes in CANDU (Canadian Deuterium Uranium) nuclear reactors that had been in contact with its calandria tubes [8].

$\mathrm{Zr}$ hydride can form in one of three crystal structures, depending on hydrogen concentration and cooling rate from solution temperature [9-15]. At low to medium concentrations, facecentred-tetragonal (fct) $\gamma-\mathrm{ZrH}$ with $c / a>1$, and face-centered-cubic (fcc) $\delta\left(\sim \mathrm{ZrH}_{1.5}\right)$ are observed. $\gamma$-hydride is metastable and its formation is favoured by fast cooling rates [15], whereas $\delta$-hydride is the equilibrium phase. $\epsilon$-hydride forms at a hydrogen concentration of greater than $\approx 62.5$ at\%, and has a fet crystal structure but with $c / a<1$.

\section{Experimental details.}

Binary zirconium alloys containing $0.36,44.3,62.8,64.3$, and 64.8 at $\% \mathrm{H}$ were prepared with the aid of pressure-temperature isotherms, as described in reference [16]. $\mathrm{Zr}$-2.5 Nb material was charged with 44.0 at $\% \mathrm{H}$ at $925 \mathrm{~K}$ from which the reaction was stopped by quenching the specimen tube in a Dewar flask of liquid nitrogen. Another $\mathrm{Zr}-2.5 \mathrm{Nb}$ specimen was charged with 65.5 at\% $\mathrm{H}$ (specimen G169) but in a different manner; pure hydrogen was created by heating uranium hydride slowly, so the $\mathrm{Zr}-2.5 \mathrm{Nb}$ specimen absorbed an increasing amount of hydrogen while being heated to $1123 \mathrm{~K}$. The specimen was then slowly cooled to room temperature, while, at the same time, the hydrogen pressure was decreased through a reduction in the temperature of the uranium hydride turnings. Thin foils of $\mathrm{Zr}-\mathrm{H}$ and $\mathrm{Zr}-2.5 \mathrm{Nb}-44.3$ at\% $\mathrm{H}$ specimens were made using a Metal Thin electropolishing machine. Foils of $\mathrm{Zr}-2.5 \mathrm{Nb}$ containing high hydrogen concentrations were brittle and difficult to electropolish to electron transparency. They generally thinned uniformly instead of being electropolished with a dimpled profile. A modified technique was employed. A relatively thick disc $(\approx 0.3 \mathrm{~mm})$ was carefully dimpled on both sides with a mechanical dimple grinder. Approximately $0.07 \mathrm{~mm}$ was left in the middle of the disc which was then electropolished with an automatic Metal Thin electropolishing machine. EEL spectra were obtained using either a Gatan serial EEL spectrometer (model 607) or a Gatan parallel EEL spectrometer (PEELS model 666). The resolution of the EEL spectrometer, defined by the full-width half-maximum of the zero loss peak, varied from $0.9 \mathrm{eV}$ with an unsaturated $\mathrm{LaB}_{6}$ filament operating at an accelerating voltage of $120 \mathrm{keV}$ to $2.8 \mathrm{eV}$ when operating with a saturated $\mathrm{LaB}_{6}$ at $300 \mathrm{keV}$. The highest resolution was employed for EEL spectra with $\epsilon$-hydride because its plasmon loss energy was observed to be only two or three tenths of an $\mathrm{eV}$ from that of $\delta$-hydride. All the low loss EEL spectra were calibrated using the plasmon peak of pure $\mathrm{Al}$, which was taken to be $15.3 \mathrm{eV}[1]$.

\section{Plasmon loss energies.}

Electron-transparent foils from $\mathrm{Zr}-0.36$ at\% $\mathrm{H}$ and $\mathrm{Zr}-44.3$ at\% $\mathrm{H}$ were employed to obtain the low loss regions of the EEL spectra for $\mathrm{Zr}, \gamma$ - and $\delta$-hydrides using the serial EEL spectrometer. The 0.36 at $\% \mathrm{H}$ specimen, identical to that used by Weatherly [17], contained $\gamma$-hydrides in a $\mathrm{Zr}$ matrix. The 44.3 at\% $\mathrm{H}$ specimen contained all three phases, $\mathrm{Zr}, \gamma$ - and $\delta$-hydrides. This 
observation is in agreement with the general accepted opinion that $\gamma$-hydride is a metastable phase produced by a martensitic shear transformation. Plasmon loss energies determined from EEL spectra of these specimens have been reported previously $[4,5]$, and are summarised in table I. The 62.8 at $\% \mathrm{H}$ specimen contained $\gamma$-and $\delta$-hydrides; two values each were obtained for the plasmon loss energies for each phase. These were 18.5 and $19.3 \mathrm{eV}$ for $\gamma$-and $\delta$-hydrides respectively.

Table I. - Experimental plasmon loss energies in $\mathrm{Zr}-\mathrm{H}$ specimens.

\begin{tabular}{|c|c|c|c|c|}
\hline \multirow{2}{*}{ Specimen } & \multicolumn{4}{|c|}{ Plasmon Loss energy (in eV) } \\
\hline & $\mathrm{Zr}$ & $\gamma$-hydride & $\delta$-hydride & $\epsilon$-hydride \\
\hline $\begin{array}{l}0.36 \text { ats } \mathrm{H} \\
44.3 \text { ats } \mathrm{H}\end{array}$ & $(16.8 \pm 0.2)_{10}$ & $(18.3 \pm 0.2)_{16}$ & $(19.2 \pm 0.2)_{14}$ & $\begin{array}{l}\text { sérial EELS } \\
\text { serial EELS }\end{array}$ \\
\hline $62.8 \mathrm{atz} \mathrm{H}$ & & $(18.5)_{2}$ & $(19.3)_{2}$ & serial EELS \\
\hline \multirow[t]{2}{*}{64.3 ats $H$} & \multicolumn{3}{|c|}{ (Serial EELS) } & $(19.6 \pm 0.5)_{10}$ \\
\hline & \multicolumn{3}{|c|}{ (PEELS) } & $(19.6 \pm 0.1)_{8}$ \\
\hline 64.8 ats $H$ & \multicolumn{3}{|c|}{ (PEELS) } & $(19.6 \pm 0.1)_{15}$ \\
\hline
\end{tabular}

Error limits represent 2 standard deviations; number of experimental measurements is given as subscript

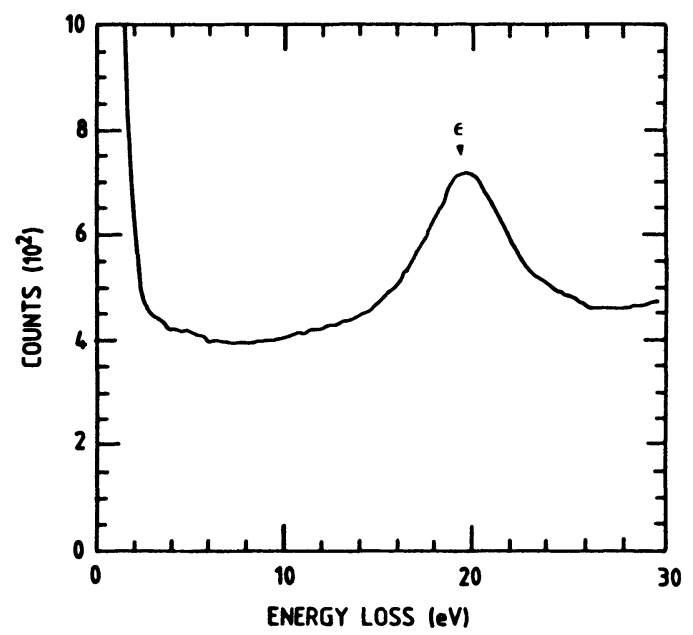

Fig. 1. - EEL plasmon spectrum of $\epsilon$-hydride in $\mathrm{Zr}-64.3$ at\% $\mathrm{H}$; plasmon loss peak at $19.6 \mathrm{eV}$. 
Initial attempts to distinguish the plasmon loss energy of $\epsilon$-hydride relative to $\delta$-hydride using serial EELS yielded inconclusive results. Further work showed that the distinction could be made if suitable collection conditions were employed. To minimize drift of the electron beam energy, it was necessary to use a very short dwell time, $10 \mathrm{msec} / \mathrm{channel}$, with the intensity of the zero-loss peak low enough to avoid saturating the detector. Ten spectra from $\epsilon$-hydride of the 64.3 at $\% \mathrm{H}$ alloy were collected and analyzed; the plasmon loss peak was at $(19.6 \pm 0.5) \mathrm{eV}$, with the error limits representing two standard deviations.

In contrast to serial EELS, unambiguous measurements were made readily using the high collection efficiency of the PEELS system. A total of twenty two spectra for $\epsilon$-hydride were collected (using dwell times of 100 to $500 \mathrm{~ms}$ ) for the 64.3 at\% $\mathrm{H}$ and the 64.8 at\% $\mathrm{H}$ specimens. One such EEL spectrum is shown in figure 1. The plasma loss peak was at $(19.6 \pm 0.1) \mathrm{eV}$ in both cases. By comparing the plasmon loss energies for $\epsilon$-hydride as determined by serial and parallel EELS (Tab. II), it is clear that PEELS offer better accuracy and reproducibility. The error limits from the serial EELS measurements also make it impossible to distinguish $\epsilon$-hydride from $\delta$-hydride unless a large number of measurements are made.

Table II. - Experimental plasmon loss energies of hydrides in $\mathrm{Zr}-2.5 \mathrm{Nb}$.

\begin{tabular}{|l|c|c|c|}
\hline Specimen & \multicolumn{3}{|c|}{ Plasmon Loss energy in (eV) } \\
\hline & $\gamma$-hydride & $\delta$-hydride & $\epsilon$-hydride \\
\hline 44.3 at8 H & $(18.3 \pm 0.2)_{8}$ & $(19.2 \pm 0.2)_{6}$ & \\
\hline 65.5 at8 H & & $(19.6 \pm 0.1)_{10}$ \\
\hline
\end{tabular}

The microstructure of the $\mathrm{Zr}-2.5 \mathrm{Nb}-44.0$ at $\% \mathrm{H}$ specimen consists of martensitic grains (Fig. 2a) and clear grains with or without twinned structures (e.g. Fig. 2b). The grain diameters were 2 to $10 \mu \mathrm{m}$. Analysis of electron microdiffration patterns from the clear grains revealed that they were fcc $\gamma$-hydride, with a lattice parameter of $0.478 \mathrm{~nm}$. The plasmon loss energy, as determined from six EEL spectra, was $(19.2 \pm 0.2) \mathrm{eV}$. The twinned structures were shown by electron microdiffraction to be fct $\gamma$-hydride, with $a=0.464 \mathrm{~nm}$, and $c=0.498 \mathrm{~nm}$. The plasmon loss energy was $(18.3 \pm 0.2) \mathrm{eV}$, analyzed from eight EEL spectra. In figure 3 are examples of EEL spectra for $\gamma$-and $\delta$-hydrides in $\mathrm{Zr}$-2.5Nb respectively. Their plasmon energies are indistinguishable from those for $\mathrm{Zr}-\mathrm{H}$ alloys, despite the alloying addition of $\mathrm{Nb}$.

TEM/AEM examination of the $\mathrm{Zr}-2.5 \mathrm{Nb}-65.5$ at\% $\mathrm{H}$ specimen (G169) revealed " $\beta$-Zr"-like filaments in a matrix of solid $\epsilon$-hydride (Fig. 4). These filaments had widths of about $20 \mathrm{~nm}$, and were spaced 0.1 to $0.3 \mu \mathrm{m}$ apart. Energy dispersive $\mathrm{X}$-ray analysis revealed a $\mathrm{Nb}$ concentration of greater than 15 at\% in the phase. Attempts to obtain good microdiffraction patterns from them were unsuccessful. Because hydrogen addition was carried out at $1123 \mathrm{~K}$ in the $(\alpha+\beta)$-filed while the specimen absorbed an increasing amount of hydrogen during heating, the filaments were thought to be hydrogen-stabilized $\beta-\mathrm{Zr}$ phase. The matrix contained about $0.7 \mathrm{at} \% \mathrm{Nb}$. Electron microdiffusion analyses were consistent with the matrix being fct $\epsilon$-hydride phase, with $a=0.492 \mathrm{~nm}$, and $c=0.456 \mathrm{~nm}$. Ten EEL spectra (e.g. Fig. 5) were collected with the PEELS system, and they were analyzed to give a plasmon loss energy of $(19.6 \pm 0.1) \mathrm{eV}$. This energy is 


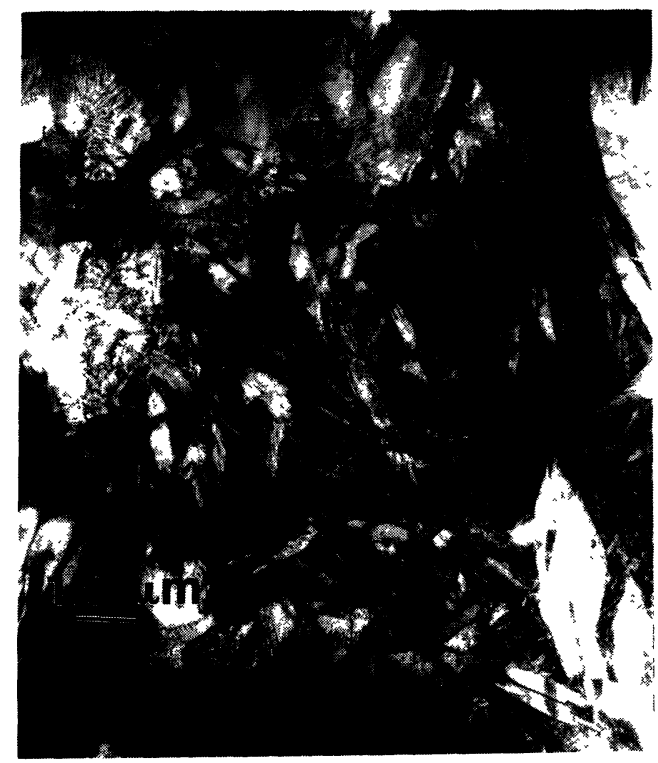

a)

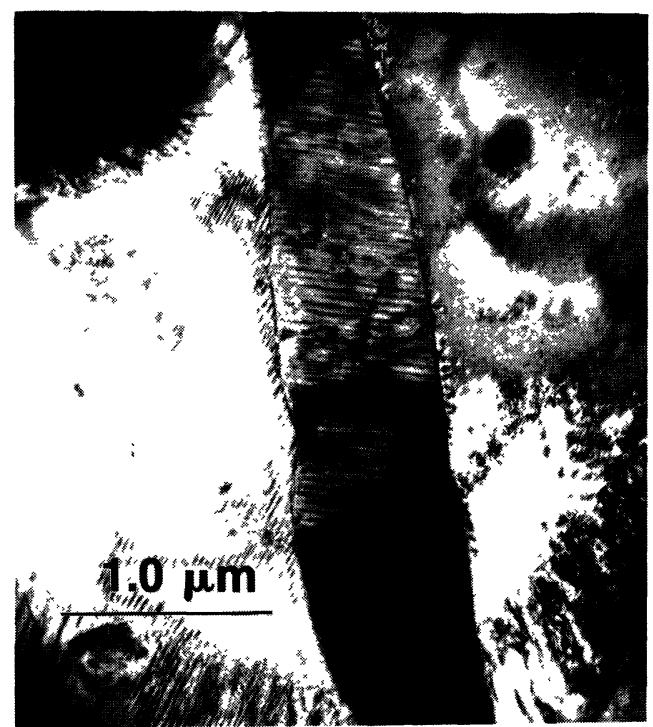

b)

Fig. 2. - Microstructure of $\mathrm{Zr}-2.5 \mathrm{Nb}-44.0$ at $\% \mathrm{H}$, showing (a) martensitic grain structure, and (b) $\delta$-hydride grain with twinned $\gamma$-hydride.

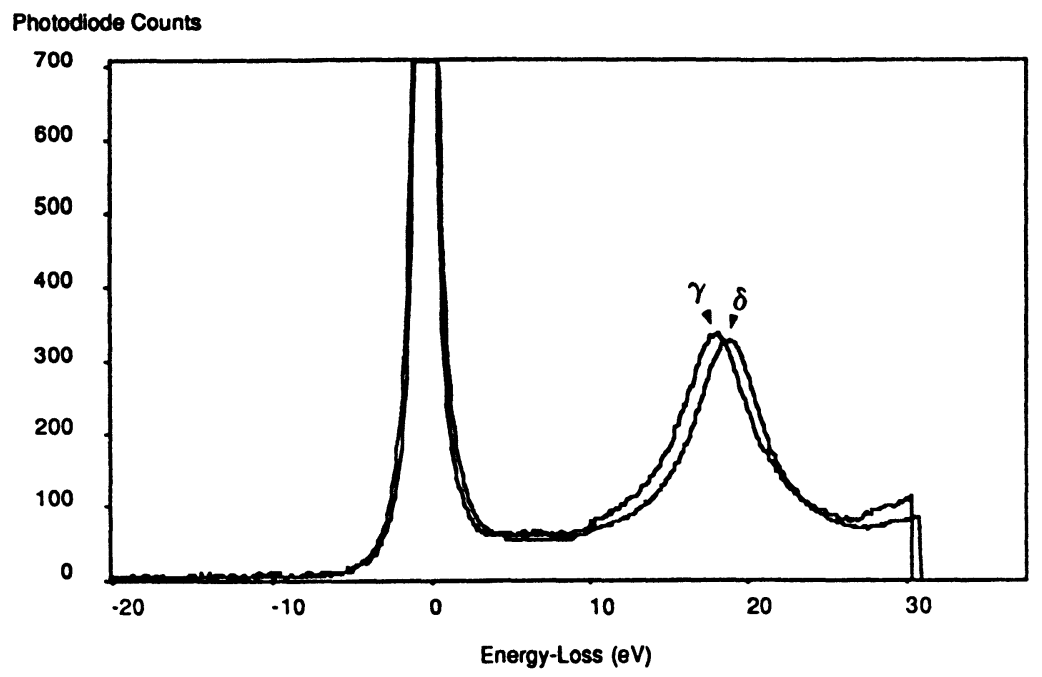

Fig. 3. - EEL plasmon spectra of $\gamma$-and $\delta$-hydrides in $\mathrm{Zr}-2.5 \mathrm{Nb}-44.0$ at $\% \mathrm{H}$ showing plasmon loss energies of $\gamma$-hydride at $18.4 \mathrm{eV}$ and $\delta$-hydride at $19.3 \mathrm{eV}$.

consistent with that for $\epsilon$-hydride in $\mathrm{Zr}$-H specimens. A summary of the plasmon energies for $\gamma$-, $\delta$ - and $\epsilon$-hydrides is given in table II. 


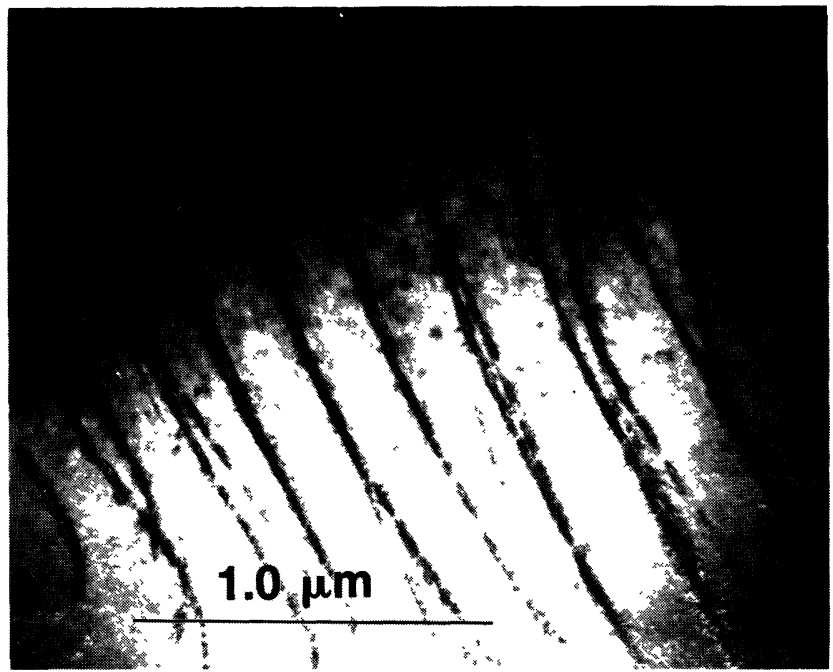

Fig. 4. - Microstructure of $\mathrm{Zr}-2.5 \mathrm{Nb}-65.5$ at $\% \mathrm{H}$ showing " $\beta$-Zr" like filaments in an $\epsilon$-hydride matrix.

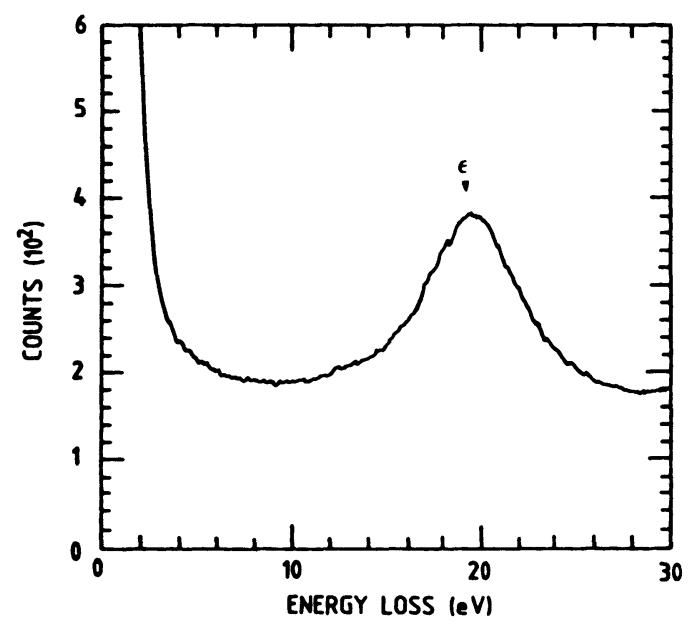

Fig. 5. - EEL plasmon spectrum of $\epsilon$-hydride in $\mathrm{Zr}-2.5 \mathrm{Nb}-65.5$ at $\% \mathrm{H}$; plasmon loss peak at $19.6 \mathrm{eV}$.

The lattice parameters of all the hydrides in $\mathrm{Zr}-\mathrm{H}$ and in $\mathrm{Zr}-2.5 \mathrm{Nb}-\mathrm{H}$ alloys, measured using electron microdiffraction patterns, are summarized in table III. Literature values are also listed for comparison. 
Table III. - Lattice parameters of hydrides in $\mathrm{Zr}-\mathrm{H}$ and $\mathrm{Zr}-2.5 \mathrm{Nb}-\mathrm{H}$ alloys.

\begin{tabular}{|c|c|c|c|}
\hline Specimen & $\gamma$-hydride & $\delta$-hydride & $\epsilon-h y d r i d e$ \\
\hline \multicolumn{4}{|l|}{$\mathrm{Zr}-\mathrm{H}$ alloys } \\
\hline 0.36 ats $\mathrm{H}$ & $\begin{array}{c}a=0.4596 \mathrm{~nm} \\
c=0.4969 \mathrm{~nm} \\
(\text { from [16]) }\end{array}$ & & \\
\hline 44.3 atg $\mathrm{H}$ & $\begin{array}{l}a=0.460 \mathrm{~nm} \\
c=0.497 \mathrm{~nm}\end{array}$ & $a=0.478 \mathrm{~nm}$ & \\
\hline Literature & $\begin{aligned} a= & 0.458 \mathrm{to} \\
& 0.460 \mathrm{~nm} \\
c= & 0.497 \mathrm{~nm} \\
& {[10-12] }\end{aligned}$ & 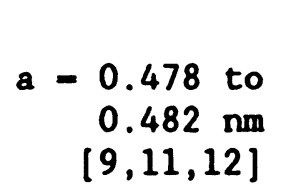 & \\
\hline 64.3 ats $H$ & & & $\begin{array}{l}a=0.490 \mathrm{~nm} \\
c=0.460 \mathrm{~nm}\end{array}$ \\
\hline 64.8 ats $\mathrm{H}$ & & & $\begin{array}{l}a=0.492 \mathrm{~nm} \\
c=0.461 \mathrm{~nm}\end{array}$ \\
\hline Literature & & & $\begin{aligned} a= & 0.476 \text { to } \\
& 0.494 \mathrm{~nm} ; \\
c= & 0.472 \mathrm{to} \\
0.446 \mathrm{~nm} & \\
& {[9,11,12] }\end{aligned}$ \\
\hline \multicolumn{4}{|c|}{$\mathrm{Zr}-2.5 \mathrm{Nb}-\mathrm{H}$ alloys } \\
\hline 44.0 ats $\mathrm{H}$ & $\begin{array}{l}a=0.464 \mathrm{~nm} \\
c=0.498 \mathrm{~nm}\end{array}$ & $a=0.478 \mathrm{~nm}$ & \\
\hline 65.5 ats $\mathrm{H}$ & & & $\begin{array}{l}a=0.492 \mathrm{~nm} \\
c=0.456 \mathrm{~nm}\end{array}$ \\
\hline
\end{tabular}

\section{EELS 'fingerprinting'}

The calibrated plasmon loss energies listed in tables II and III can be used for 'fingerprinting' hydride phases in $\mathrm{Zr}$ and $\mathrm{Zr}-\mathrm{Nb}$. This technique has been shown to be successful in phase identification in a specimen of $\mathrm{Zr}-44.3$ at\% $\mathrm{H}$ where all three phases, $\mathrm{Zr}$, $\gamma$-hydride co-exist (Fig. 6). EEL spectra were taken from each of the regions to locate the plasmon loss peaks. Based on these peak values, the phases corresponding to each region were identified and subsequently verified with microdiffraction results [4]. It would have been possible to identify the hydride species by 
electron microdiffraction, but the EELS fingerprinting technique is very much faster, because an EEL spectrum can be acquired and analyzed on-line in minutes, compared to several hours by electron microdiffraction.



Fig. 6. - Regions analyzed in a thin foil of $\mathrm{Zr}-44.3$ at\% $\mathrm{H}$ and identified after the EELS results.

The EELS fingerprinting technique is best illustrated for hydride phase identification in hydride blisters grown on $\mathrm{Zr}-2.5 \mathrm{Nb}$. The information can be used as a basis for comparison with predictions from the blister growth model. Typically the centre of a blister older than 3 months is made up of $\delta$-hydride, while the phases at the edge are mixtures of $\gamma$-and $\delta$-hydrides. An example of a fine-grained $\gamma$-hydride region at the edge of a blister on $\mathrm{Zr}$ - $2.5 \mathrm{Nb}$ pressure tube aged for seven months is shown in figure 7. Because of the complexity of the microstructures of blisters, which contain high dislocation densities and sometimes twins, the EELS fingerprinting technique is clearly superior to electron diffraction for routine analyses. Moreover, EELS has the advantage of being able to probe into very fine grains, $\sim 0.5 \mu \mathrm{m}$, in $\mathrm{Zr}-2.5 \mathrm{Nb}$ pressure tube, while it would be very difficult to obtain microdiffraction patterns from such small areas.

\section{Conclusions.}

This article describes an EELS plasmon fingerprinting technique used in identifying $\mathrm{Zr}, \gamma$ - and $\delta$-hydrides and extended to $\epsilon$-hydride. The plasmon loss energy of $\epsilon$-hydride was found to differ by only about two-tenths of an $\mathrm{eV}$ from that of $\delta$-hydride. Experiments revealed that paralell EELS offered better accuracy and reproducibility than serial EELS in detecting such small energy difference. The energy peaks will be useful for fingerprinting phases in solid hydride specimens and in hydride blisters grown on $\mathrm{Zr}-2.5 \mathrm{Nb}$ pressure tube. 


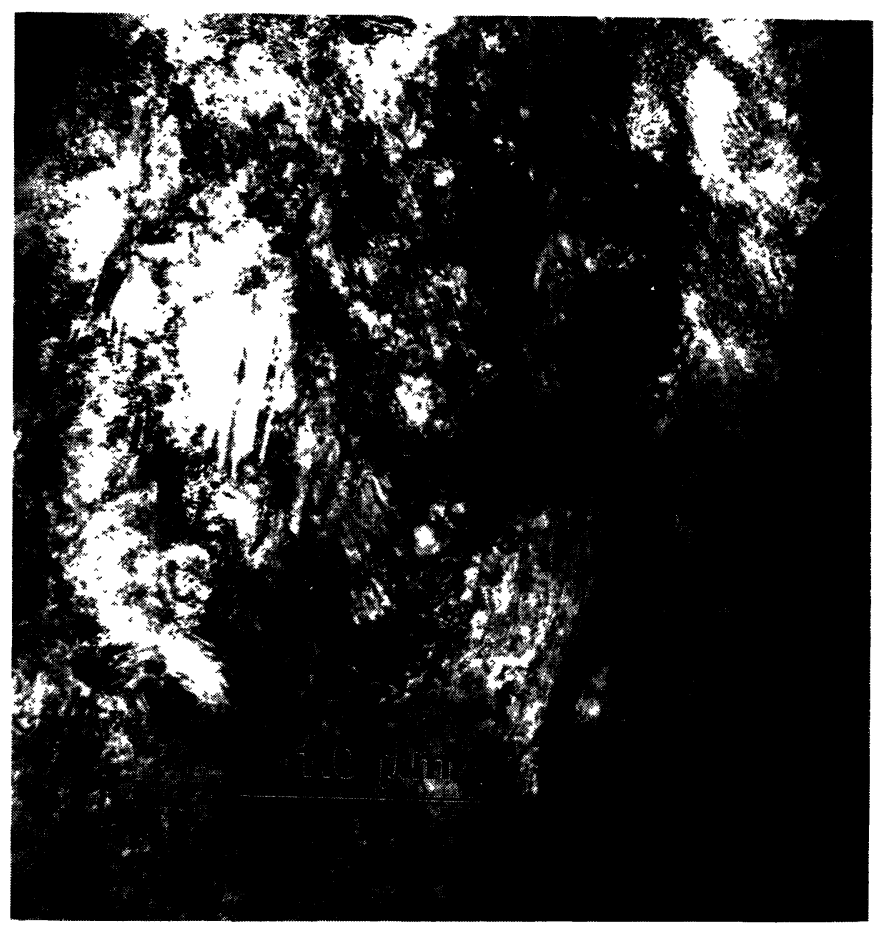

Fig. 7. - File-grained $\gamma$-hydride region in an aged blister on $\mathrm{Zr}-2.5 \mathrm{Nb}$.

\section{Acknowledgements.}

The authors are most grateful to Drs. C. D. Cann, C. K. Chow and M. P. Puls, for supplying the hydride and blister specimens. We would like to thank R. C. Styles, R. W. Gilbert, V. C. Ling, J. C. Owens, and D. P. McCooeye for experimental assistance. This work is supported by Candu Owners Group (COG), Working Party 31 (DHC and Fracture), Work Package 6530.

\section{References}

[1] Williams D.B. and EDington J.W., J. Micros. 108 (1976) 113.

[2] CUNDY S.L. and GRUNDY P.J., Philos. Mag. 14 (1966) 1233.

[3] Zaluzec N.J., Schober T. and WestlaKE D.G., in 39th Annual Proceedings, Electron Microscopy Society of America, G.W. Bailey ed. (Claitor's Publishing, Baton Rouge, Louisiana, 1981) p. 194.

[4] ZaLUZEC N.J., Schober T., Veal B.W. and Westalake D.G., in Analytical Electron Microscopy, R.H. Geiss Ed. (San Francisco Press, 1981) p. 191.

[5] WOO O.T. and CARPENTER G.J.C., Scripta Metall. 20 (1986) 423.

[6] WOO O.T. and CARPENTER G.J.C., Proceedings, 11th International Congress on X-ray Optics and Microanalysis, J.D. Brown and R.H. Packwood Eds. (London, Canada, 1986) p. 396.

[7] LEGER M., MOAN G.D., WALlACE A.C. and WATSON N.J., in Zirconium in the Nuclear Industry: Eighth International Symposium, ASTM STP 1023, P. Van Swam and C.K. Eucken Ed. American Society for Testing and Materials (1989) p. 50.

[8] FIELD G.J., DuNN J.T. and CHEADLE B.A., Canadian Metall. Quart. 24 (1985) 181. 
[9] MOORE K.E. and Young W.A., J. Nucl Mater. 27 (1968) 316.

[10] SidHU S.S., SALYA MURPHY N.S., CAMPOS F.P. and ZAUBERIS D.D., Adv. Chem. Series 39 (Am. Chem. Soc.) 1963 , p. 87.

[11] BECK R.J., A.S.M. Trans. Quarter. 55 (1962) 546.

[12] BARRAClOUgH K.G. and BEEVERS C.J., J. Nucl. Mater. 34 (1970) 125.

[13] ZuZEK E., ABRiata J.P., SAN-MARTIN A. and MANCHESTER F.D., Bull. Alloy Phase Diagram 11 (1990) 385.

[14] NORTHWOOD D.O. and KOSSAIH U., Int. Metals. Rev. 28 (1983) 92.

[15] NATH B., LORIMER G.W. and RIDLEY N., J. Nucl. Matter. 49 (1973) 262.

[16] SIMPSON L.A. and CANN C.D., J. Nucl. Mater 87 (1979) 303.

[17] WEATHERLY G.C., Acta Metall. 29 (1981) 501. 